\title{
Reflection: Using Photovoice to Encourage Mastering Vocabularies for Computer Science Students
}

\author{
F Nurhidayati ${ }^{1}$, A Cipto ${ }^{2}$, H Hafid ${ }^{3}$, S Mahmudah ${ }^{4}$, M.A. Gunawan ${ }^{5}$ \\ \{Fitrinurhidayati@dosen.umaha.ac.id ${ }^{1}$,harapinhafid14@gmail.com ${ }^{2}$ \} \\ ${ }^{1}$ Accounting, Economy Faculty Maarif Hasyim Latif University Sidoarjo, Indonesia \\ ${ }^{2}$ Computer science,Maarif Hasyim Latif University Sidoarjo, Indonesia \\ ${ }^{3,4,5}$ Animal Science Departement, Faculty of Animal Science, Halu Oleo University, Indonesia
}

\begin{abstract}
Mastering vocabulary is an important thing because, without it, we don't understand the text. Further, we can't speak if lack of vocabulary. In contrast, English is a unique language because one word can different meaning in a different context. So, understand the context is important too. In addition, computer science students should understand the specific vocabulary related to their field. But, more of them difficult to understand because don't know the specific meaning. This study aimed at how to improve mastering vocabularies for computer science through reflecting. It was a qualitative descriptive approach. Data collection method was documentation through photovoice and test result. The analysis was documentation analysis. A sample of data was computer science students in second grade. The result was photovoice could represent what students' problem and reflection they knew the mistake so, they can improve mastering vocabulary in computer science.
\end{abstract}

Keyword: Photovoice, reflection, vocabulary, computer science students

\section{Introduction}

Vocabulary is one aspect of English that have to take important part to learn it. Even more, it will lead the learners to understand and the first step to learning the other aspects of English. It is fundamental to fluent English, including; reading, speaking, writing, and listening. Chen[1] indicated that reading ability and vocabulary knowledge are two of the most important components of performance in a second language and depend on the other, especially in an academic setting. Poor English vocabulary can impart others. To read English articles fluently, a learner must understand at least 2000 commonly used English words.Mastering English vocabularies is central to English language acquisition. For example in speaking, without vocabulary, it like speak without meaning. Speakers don't know how to speak. It like a window or way to track another stage of the English language. It is the way to explore information. Since the English language to be a second language in many countries, development in researching and modify the method in teaching English grow rapidly. Due to English learning is an important and English has specific characteristic than the other's language. The specific characteristics are different field has a different vocabulary. For example, in law, it has specific vocabulary and on the other hand in economics has the same too. It makes difficulties for learner English as a second language. We should rich in 
vocabulary. So, mechanical students have the same problem when they learn English or other materials related to computer science. Almost touches book convey the English language so that they should mastering English for computer science.

Reflection is a method to observe the student's mistake. It is related to a learning experiment. "Reflection" is a key concept in adult education theory and more specifically within experiential learning discourses[2].It is understood that it has a correlation with mental consciousness. Reflective practice is a pedagogic tool used widelywithin formal, informal, individual, and organizational learning activities and processes.

The concept and practice of reflection have undergone considerable change and development in its definition and application[3] and take different forms in different contexts and considering reflection inherent in cognitive awareness.

Due to reflecting is a metal experience, it is difficult to show the condition.And reflective learning is involved in experiential learning, but they do not coincide completely[4].So that photovoice is one method to record. According to Wang[5], photovoice is a process by which people can identify, represent, enhance their community through a specific photographic technique. Hence, "Photovoice" is a participatoryaction research methodology based on the understanding that people are experts in their own lives[6].Answers the question of why the situation exists? What do you see here? What is really happening? What can we do about the condition?[6].

\section{Research Method}

This research was conducted in the technology of information class, which took photovoice for the media to got data. This research was involved in three phases first is students serve severals vocabularies deal with ESP, and the second they observe the mistakes them associate with pronunciation, appropriate words place, meaning. And the last from knowing the mistakes they did the test with the right one. This study used a visual methodology called photovoice. It uses photography to gain participatory report[7].

\section{Result and discussion}

Based on the treatment in computer science students took, they have some obstacles in mastering vocabularies, especially in ESP. In test fist figure 1

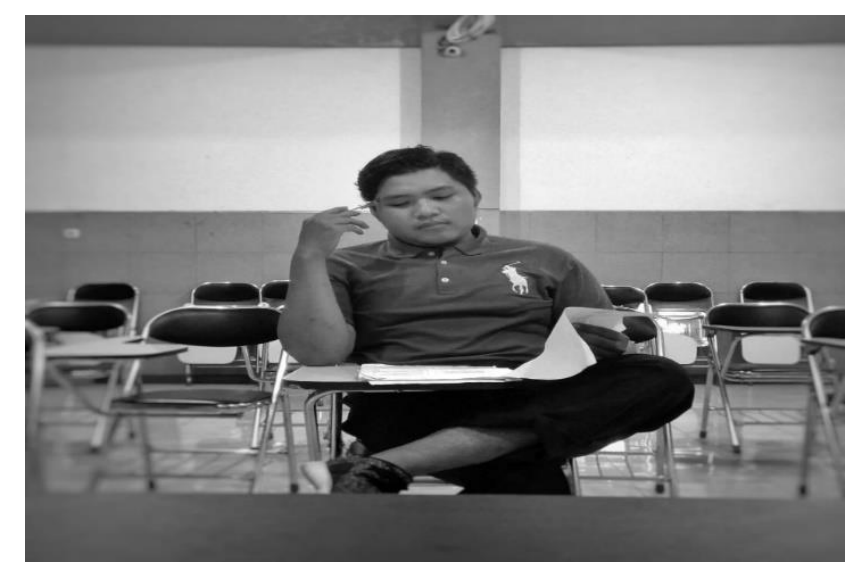


He looked confused when asked to explain some words regarding vocabulary for computer science.

Some problems arose when a word has a different function in a particular field of knowledge. Like figure 1 shown that students who have not learned before looked difficulties and straight with those words. In assessments phase, students should interpret some words in its function. They thought why can't do it. It reflection process in the beginning. Observation of the particular condition related to the students done. Further, it is a challenge for them to explore their knowledge related to new words. This reflection may be reflected with condition what they did. Through the photo students, observe written reflection is often considered to be a required component of a learning portfolio and is what distinguishes a learning portfolio from a scrapbook, photo album, or web page. These reflections may be associated with individual artifacts and with groups of artifacts[8].Figure 2

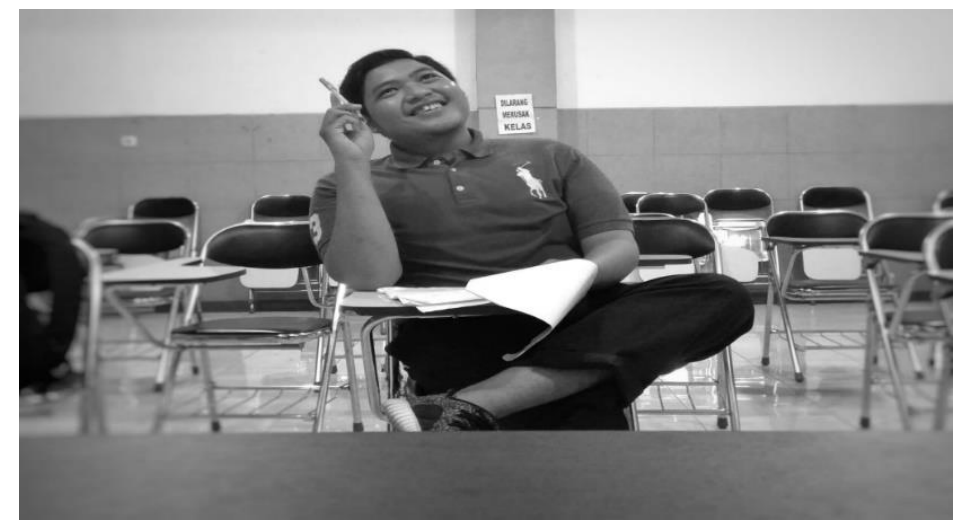

He looked very happy when he describe words in its functions, and in reflection, he knows the mistake.

Figure 2 students shown the photo and look like more enjoy and feel happy with their task. Photovoice addresses to describe and beyond the real condition. In this case to enrich vocabulary in computer science. Maybe one word is commonly used in computer science, but when to ask to explain it may have difficulty. Like "the mouse" in prior knowledge is a feature oval round contain two buttons right and left. But when asked to explain it associated with function Or some words obvious but after seeing the photo students because of, nowadays many students don't their mind to the overcome the problem and a more using gadget or searching on the internet, it is not good because can imply the dependency in learning and effect in lifestyle. Pada figure 2 shown they looked difficulties faster to finished it. Because one good way to learn is from experience. Mastering vocabulary is not enough, only known how much word but how deep they understanding it [9].

\section{After reflection}

"Mouse" most people know it is a tool to operate commands on computers whose original meaning is rats. Students know the physical form of "Mouse," but when describing the functions and meanings of words, students have difficulties.

But in their minds, they know what is meant by "Mouse" because the word is often used when operating a computer. The word "fax" is no stranger now. Students refer to their function to describe. According to Meriam-Webster keyboard, a musical instrument that is 
played by means of a keyboard like that of piano and that produces sounds electronically. A computer keyboard is one of the primary input devices used with a computer. Similar to an electric typewriter, a keyboard is composed of buttons that create letters, numbers, and symbols, as well as perform other functions. Based on the two explanations from the two different campuses, it can be seen that the keyboard functions are almost the same, only those that are produced differently. Like most people understanding keyboard is a tool consisting of various baseball to produce something. But it is different from the word "fan". Generally, the word "fan" is an object to produce wind that can refresh the air. But what if the word "fan" is related to a device on a computer. The word "fan" is not much different from the functions that are usually used by everyday people. But if it is connected to a device on the computer the difference lies in the object being targeted. If the "fan" is used in general it cools the room, but if the "fan" on the computer to cool the tools or components on the computer or laptop[10]. Having a functional equation is only different in the object imposed, resulting in students being able to easily describe the function and purpose of the component.

\section{Conclusion and suggestion}

In this study, we have known that after reflection that is shown through photovoice students understand that some vocabularies has different meaning and related to its meaning. Reflection effect they know what their weakness and realized to learn with preparation. Regarding meaning, some words depend on function but a different object. Their prior knowledge knows that the function of some words but difficult to explain. And when they looked at the photovoice they know what the mistakes. Through this study, hopefully engineering students can mastering vocabulary especially, for computer science.

\section{References}

[1] C. M. Chen and C. J. Chung, "Personalized mobile English vocabulary learning system based on item response theory and learning memory cycle," Comput. Educ., vol. 51, no. 2, pp. 624-645, 2008.

[2] R. Jordi, "Reframing the concept of reflection: Consciousness, experiential learning, and reflective learning practices," Adult Educ. Q., vol. 61, no. 2, pp. 181-197, 2011.

[3] K. Illeris, "What Do We Actually Mean by Experiential Learning?," Hum. Resour. Dev. Rev., vol. 6, no. 1, pp. 84-95, Mar. 2007.

[4] J. A. Moon, A handbook of reflective and experiential learning: Theory and practice. London: Routledge, 2013.

[5] C. Wang and M. A. Burris, "Photovoice: Concept, Methodology, and Use for Participatory Needs Assessment," Heal. Educ. Behav., vol. 24, no. 3, pp. 369-387, Jun. 1997.

[6] C. C. Wang, S. Morrel-samuels, P. M. Hutchison, L. Bell, and R. M. Pestronk, "Flint photovoice: Community building among youths, adults, and policymakers," Am. J. Public Health, vol. 94, no. 6, pp. 911-913, 2004.

[7] K. MACLEAN and E. WOODWARD, "Photovoice Evaluated: An Appropriate Visual Methodology for Aboriginal Water Resource Research," Geogr. Res., vol. 51, no. 1, pp. 94-105, Feb. 2013.

[8] H. L. Chen, D. Cannon, J. Gabrio, L. Leifer, G. Toye, and T. Bailey, "Using Wikis and Weblogs to Support Reflective Learning in an Introductory Engineering Design Course," Am. Soc. Eng. Educ. Annu. Conf. Expo., pp. 1-11, 2005. 
[9] H. Huntley, "Essential Academic Vocabulary:Mastering the Complete Academic Word List," CATESOL J., vol. 19, no. 1, pp. 210-219, 2007.

[10] J. Marks, Check Your English Vocabulary for Computers and Information Technology: All you need to improve your vocabulary. London: A\&C Black, 2007. 